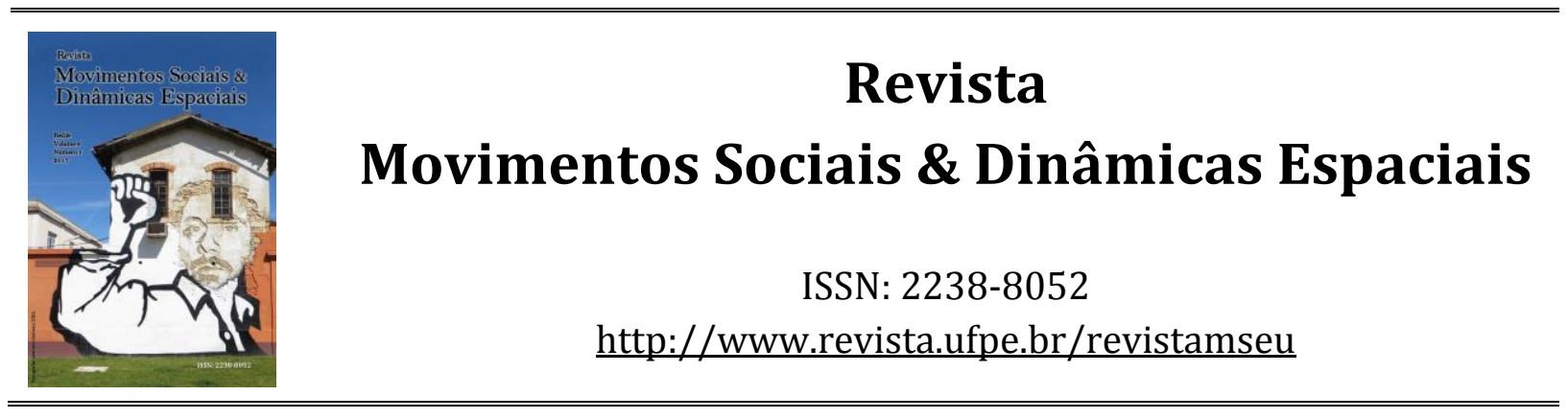

Artigo recebido em 14/05/2017 e aceito em 18/07/2017.

\title{
RELAÇÕES SOCIEDADE E NATUREZA, PADRÕES DE CIENTIFICIDADE E PERSPECTIVAS POSSÍVEIS PARA ESTUDOS AMBIENTAIS
}

\author{
SOCIETY AND NATURE RELATIONS, SCIENTIFIC STANDARDS AND POSSIBLE \\ PERSPECTIVES FOR ENVIRONMENTAL STUDIES
}

Manuela Maria Pereira do NASCIMENTO ${ }^{1}$

\begin{abstract}
RESUMO
No momento atual, emergem fortemente questões que dizem respeito não apenas ao status científico de uma teoria, ao método de pesquisa ou sobre quem pode ou deve realizá-la. Dentre tais questionamentos, observaram-se nesse trabalho, tendências que abordam a forma de observação e tratamento dos objetos em estudo, bem como a influência e efeitos da atividade científica na sociedade e natureza. Tais tendências foram discutidas a partir do levantamento bibliográfico de trabalhos com elementos teórico-metodológicos que contribuem, nesse sentido, para a fundamentação de estudos ambientais. Os autores pesquisados pautam suas considerações na necessidade de mudança de paradigmas em relação à atividade científica, na revisão de desdobramentos dos resultados obtidos e reflexões sobre as responsabilidades quanto às informações geradas.
\end{abstract}

Palavras-chaves: sociedade e natureza, ciência livre de valor, senso comum, complexidade.

\begin{abstract}
At the present moment, questions about not only the scientific status of a theory, the method of research or about who can or should do it, emerge strongly. Among these questions, it was observed in this work trends that deal the way of observation and treatment of the objects of study, as well as the influence and effects of scientific activity on society and nature. Such tendencies were discussed from survey of works with theoretical and methodological elements that contribute, in this sense, to the foundation of environmental studies. The surveyed authors base their considerations on the need to change of paradigms in relation to the scientific activity, in the review of the consequences of the obtained results and reflections about the responsibilities regarding the generated information.
\end{abstract}

Keywords: society and nature, science value-free, common sense, complexity.

\footnotetext{
${ }^{1}$ Doutoranda no Programa de Pós-Graduação em Desenvolvimento e Meio Ambiente da Universidade Federal de Pernambuco, UFPE. Membro do Grupo de pesquisa Movimentos Sociais e Espaço Urbano MSEU. E-mail: manuelanascimento@yahoo.com.br.
} 


\section{INTRODUÇÃO}

No momento atual, compreendido por alguns estudiosos como um ambiente de pósmodernidade, emergem fortemente questões que dizem respeito não apenas ao status científico de uma teoria, ao método de pesquisa ou sobre quem pode ou deve realizá-la. Dentre tais questionamentos, residem a influência e efeitos da atividade científica na sociedade e natureza. Agora, mais intensamente que em outras épocas, principalmente considerando as maiores possibilidades de difusão da produção científica e acesso à informação, avaliam-se criticamente inter-relações entre: ciência e sociedade, ciência e tecnologia, ciência e ética, ciência e ambiente, dentre outras.

Logo, na proposta de ciência na pós-modernidade, tem havido conexões que recuperam temas como senso comum, autonomia, ética, neutralidade, estratégias de interação, imparcialidade, crises de paradigmas, complexidade e imbricações entre ciência, tecnologia e sociedade. Ocorre a observação de atitudes, posturas, valores e responsabilidades do cientista não só como pesquisador, mas como cidadão. Suas práticas deverão ser analisadas não apenas pela relevância das suas contribuições científicas, mas, ao mesmo tempo, do ponto de vista das suas implicações.

Dentre outros autores, Hugh Lacey, Boaventura de Souza Santos e Edgar Morin têm fundamentado e produzido discussões nesse sentido. A partir de um levantamento bibliográfico que foi conduzindo a leitura para momentos anteriores do "fazer científico", foram realizadas considerações a respeito de parte de seus pontos de vista, pelos quais influências e efeitos da atividade científica são incorporados à discussão do papel da ciência.

Mais especificamente, depois de recuperadas interpretações da relação conhecimento científico, sociedade e natureza, observou-se a proposta de aproximação entre ciência e senso comum em Boaventura; a retomada mais profunda feita por Lacey da tradicional contenda inserção versus isenção de valores, na sua "[...] abordagem alternativa à questão do que constitui um juízo científico correto." (LACEY, 1998. p. 61). Mais resumidamente ao final, foram ressaltados os princípios do anel recursivo e do anel retroativo do paradigma da complexidade de Edgar Morin, uma vez que a revisão sobre o autor ainda será complementada. A presença ainda que resumida do autor neste escrito, decorre da influência da noção de complexidade por ele discutida no desencadear da revisão bibliográfica como um todo, sendo os elementos por ora mencionados, essenciais na construção das reflexões.

Nestes autores, há três perspectivas que se relacionam intrinsecamente com questões relativas à forma de observação e análise dos objetos de estudo, à influência e aos efeitos da ciência no ambiente. Na observação e análise, tem-se a busca pelo complexo, que trás consigo o 
desfazimento da exclusividade da "separação por partes", experimentação e/ou análise quantitativa, como meio para alcançar resultados científicos com credibilidade. No que tange à influência, tem-se a difusão de sua produção, refletida na possibilidade da formação de um novo senso comum e; na questão dos efeitos, de sua utilização como fonte de inovação técnica, na qual, a recuperação de determinados valores poderia garantir uma maior integridade e responsabilidade nestas inovações.

No texto que segue, considerou-se pertinente realizar de início, uma revisão de interpretações da relação sociedade e natureza, tendo em vista discutir suas tensões e conexões, afim de que essa relação traduza-se em complementaridades teórico-práticas no seu contato com a ciência. Isso, partindo do pressuposto que essa relação e a atividade científica "determinam-se mutuamente".

Logo após, apresenta-se uma breve reconstituição de elementos do contexto científico até meados do século XX; a fim de recuperar a noção de valores e autonomia identificada em Karl Popper e Thomas Kuhn, considerando que suas obras tiveram grande repercussão na atividade científica do século passado, além de sua persistência como referenciais; seguidas por contribuições para a chegada do que alguns autores denominam "pós-modernidade" e assim, chegar-se às perspectivas de Boaventura de Souza Santos, Hugh Lacey e Edgar Morin.

\section{RECUPERANDO INTERPRETAÇÕES DA RELAÇÃO SOCIEDADE E NATUREZA NA ATIVIDADE CIENTÍFICA}

Todo conhecimento é uma reconstrução/tradução por um espírito/cérebro numa certa cultura e num determinado tempo.

(MORIN, 1999, p. 34).

\subsection{Voltando ao passado?}

As formas de concepção e uso do meio natural, em se tratando das dinâmicas humanas, suscitam posturas distintas de supressão da natureza. A complexidade dos problemas que se apresentam nas interações homem-meio na atualidade, do ponto de vista analítico ou empírico, exige grandes esforços de especialização ou generalizações que envolvem inúmeras variáveis. Essas, quando não seguramente conectadas, produzem exercícios amplos e envolventes de racionalidade, porém em grande medida desprovidos de empatia com a realidade tanto do "lado humano" como do "lado natural".

Sabe-se que em algum momento, a razão técnica, instrumental e artificial sobrepõe-se à sensação espontânea de complementaridade com a natureza, a um tipo de bem-estar que não está associado às "grandes máquinas" mencionadas por Giordano Bruno no Século XVI. 
Entretanto, como não é possível precisá-lo, o intento é resgatar algumas ideias expostas desde um momento em que a artificialização da natureza ainda não compunha a tão complexa trama que ocorre nos dias atuais. Mas porque retornar às formas de observação das relações entre sociedade e natureza do passado?

Para Prigogine (1996, p. 158), "a ciência é um diálogo com a natureza" e "as peripécias desse diálogo foram imprevisíveis". 0 autor complementa sua percepção questionando como é possível tal diálogo afirmando:

Um mundo simétrico em relação ao tempo seria um mundo incognoscível. Toda mediação, prévia à criação dos conhecimentos, pressupõe a possibilidade de ser afetada pelo mundo, quer sejamos nós os afetados, quer sejam os nossos instrumentos. Mas o conhecimento não pressupõe apenas um vínculo entre o que conhece e o que é conhecido, ele exige que esse vínculo crie uma diferença entre passado e futuro. A realidade do devir é a condição sine qua non de nosso diálogo com a natureza (PRIGOGINE, 1996, p. 158).

Daí se pode responder à questão. 0 sentido não é periodizar ou retornar ao passado, mas sim confrontar momentos perceptivos em relação ao fazer humano/técnico-científico no curso da história. Isso, na busca de evidências de avanços ou retrocessos na relação sociedade e natureza, também considerando que, se na associação entre os problemas e soluções gerados, estaríamos realmente ultrapassando um estado estacionário do ponto de vista dessa relação ou se, apenas, surgem necessidades contingentes da sociedade e por elas, artificializamos e suprimimos a natureza.

\subsection{Do pensamento contra-hegemônico ao reconhecimento dos efeitos das ações humanas}

Em um cenário de hegemonia de interesses religiosos atrelados a fatores políticoeconômicos, na transição da Idade Média para a Idade Moderna, Giordano Bruno, ousou apresentar sua obra "Acerca do Infinito, o Universo e os Mundos" [1548]2. Nela, a partir de diálogos e argumentos filosóficos, tratou-se da expansão dos limites do espaço-tempo, da Terra e de seus elementos, bem como integrou o ser humano e suas criações à natureza (considerando sua constituição física, que seria igual à de qualquer outro ser animado ou inanimado). Em se tratando da hierarquia e diferenças entre todas as coisas, desde corpos celestes, vapores ou lagos, até às doenças que afetariam os seres humanos, ele afirmou:

Não nego a distinção, pois deixo cada um distinguir, a seu bel-prazer, as coisas naturais; mas nego esta ordem, esta disposição, isto é, que a terra seja

\footnotetext{
${ }^{2}$ Ao longo do texto, o ano original de publicação de materiais bibliográficos publicados antes do Século XX, será destacado dessa forma.
} 
circundada e contida pela água, a água pelo ar, o ar pelo fogo, o fogo pelo céu. Porque afirmo ser apenas um o continente e receptáculo de todos os corpos e das grandes máquinas que vemos como que disseminados e esparsos neste amplíssimo campo: onde cada um destes corpos, astros, mundos, lumes eternos, é composto daquilo que se chama terra, água, ar, fogo. (BRUNO, [1548]1973, p. 57).

Nota-se que Giordano Bruno inseriu a ideia das "grandes máquinas" nesse conjunto que observava, integrando as criações humanas na ordem que ele nega existir entre as coisas naturais, havendo assim em suas ideias, sem distinção entre o que seria correspondente à natureza e o que seria o "mundo humano". Entretanto, o que manifestava de fato era a noção de que todas as coisas estavam drasticamente separadas, afinal, ele apresentava um elo para contestar aquilo que se tinha feito da condição humana até então, seja na sua noção da Terra e sua natureza ou do Universo, por motivos religiosos ou míticos, por meio da ciência (idealismo ou racionalidade) ou das políticas que emergiam com o curso da civilização.

Bastante mencionado como precursor da ideia de dominação e controle do homem sobre o meio, opinião hoje contestada por reavaliações de seus escritos originais (SOUZA, 2008; HORA, 2015), Francis Bacon, em “A Sabedoria dos Antigos” de 1609, interpretou antigos mitos e fábulas, demonstrando a racionalidade e ensinamentos em seu conteúdo, enquanto discutia valores relativos à natureza, ciência e ética (HORA, 2015). Nesta obra, na sua tentativa de aprimorar o conhecimento da natureza, Bacon considerou que os mitos são uma espécie de disfarce que os antigos impunham à sua infinita sabedoria para que houvesse um maior entendimento dela por parte de todos (SOUZA, 2008).

Nesta volta aos tempos dos "Antigos", Bacon ([1609]2002) retomou o mito de Pã, considerando-o uma elaborada descrição da natureza universal; e a partir de sua interpretação, estabeleceu, pelo menos, duas possibilidades para se compreender a origem da natureza: uma divina e outra atomista/materialista, sendo as duas complementares e aceitáveis. A natureza foi interpretada por Bacon como a universalidade das coisas e também sua infinita multiplicidade, é ela que propicia o movimento constante e a possibilidade de existência de todos os seres, mas não necessita de complementaridade como eles, pois ela usufrui-se por si só e das coisas nela contidas.

Bacon ([1609]2002) associou detalhadamente a forma física de Pã com elementos da natureza - dos seus pontiagudos chifres (montanhas que riscariam os céus) aos seus pés de bode (movimento dos corpos terrestres na busca por elevação), de sua longa barba (raios de sol por entre as nuvens) à sua flauta (harmonia) e seu cajado (a ponta curva exprime o reto e o torto na natureza), dentre outras comparações. Também trouxe a relação do ser humano com o mundo natural, por meio da divindade que o ser representava, dizendo que 
Nada explica melhor a função de Pã que o epíteto de deus dos caçadores: toda ação natural, todo movimento e todo processo da natureza nada mais são que uma caçada. As ciências e as artes caçam suas obras, as decisões humanas caçam seus objetivos e todas as coisas da natureza ou caçam alimento, que é como caçar presa, ou prazeres, que é como caçar recreação. E também aqui, segundo métodos habilidosos e solertes. [...] Pã é, igualmente, o deus dos camponeses, pois estes vivem mais de acordo com a natureza, enquanto, nas cidades e cortes, a natureza é corrompida pelo excesso de cultura. (BACON, [1609]2002, p. 36-37).

Quando Bacon expressou que ao mesmo tempo Pã é Deus dos caçadores e dos camponeses, colocou vasta possibilidade de usos simultâneos daquilo que a natureza oferece e fez seus julgamentos a partir das contradições de tais usos, pontuando a sagacidade dos métodos humanos e a influência negativa do que chama de "excesso de cultura" nas cidades.

Percebe-se que, enquanto Giordano Bruno inseriu completamente os seres humanos nesse "conjunto natural" abolindo hierarquias, Bacon estabeleceu uma biformidade na natureza (considerando que existe uma hierarquia entre o ser humano e os outros animais, por meio da forma meio humana de Pã), mas mesmo assim, as dualidades estariam inseridas em uma natureza universal.

Estes autores representam, portanto, dois posicionamentos filosóficos relativos à natureza no que diz respeito à sua existência do plano material/racional, ou seja, como substância, princípio vital e do movimento ou então, com o sentido de Universo, do ordenamento e da conexão causal entre todas as coisas (RAFFAELLI e MAKOWIECKY, 2000). Tais posicionamentos vão ganhando novos elementos e tornando-se mais complexos com o passar do tempo, por exemplo, com o desenvolvimento das noções entre a conexão entre os fenômenos por Kant, das teorias de Marx e Engels ou a da incompletude de Gödel, dentre outras.

Naquele contexto, o processo de afastamento da natureza ainda estava prestes a se intensificar mais drasticamente, então ainda era possível unificar completamente ou dualizar ser humano e natureza num movimento consciente do pensamento. Mesmo considerando que os seres humanos já haviam devastado muitas florestas e rios nas regiões de ocupação mais adensadas da Europa, e que a assombrosa destruição ambiental das colônias estava afigurandose, ainda não havia um quadro formal das consequências dessas ações como existe hoje, apesar da crescente proliferação de doenças e da escassez desigual de recursos.

Quando se menciona um quadro formal de efeitos, não se desconsidera aqui a existência de manifestações quanto ao mal uso de elementos da natureza e suas consequências (de origem sobrenatural ou materialista), encontradas em registros muito mais remotos. Trata-se da existência de um quadro em que as questões foram sendo sistematizadas, tornando-se "mais observáveis cientificamente", o que veio a ocorrer mais afirmativamente apenas no século XX. 
De qualquer forma, nota-se que, nos primórdios da constituição da ciência moderna, independentemente de suas contribuições para o desenvolvimento de áreas específicas do conhecimento, os cientistas tratavam de analisar as ações humanas enquanto ocorriam revolucionários progressos científicos e tecnológicos. Naquele instante, já se avaliava questões complexas em relação à influência dos engenhos humanos sobre o meio, levando em conta não apenas questões de sobrevivência e do uso de recursos, mas também sua interface com a religião, a ética e a qualidade da vida em sociedade. Galileu Galilei, em uma de suas cartas que tratavam da relação entre ciência e fé, escritas em 1615, questiona:

[...] Quem pretende pôr termo aos engenhos humanos? Quem poderá assegurar que já se viu e já se sabe tudo o que há no mundo para ser sentido e sabido? Talvez aqueles que em outras ocasiões confessam (e com grande verdade) que 'as coisas que sabemos são uma parte mínima das que ignoramos'. [...] Não se deverá, pois, [...] fechar o caminho ao livre filosofar a respeito das coisas do mundo e da Natureza como se elas já tivessem sido todas reconhecidas e reveladas com certeza. Não se deveria julgar temeridade o não acomodar-se com as opiniões já tidas como comuns. (GALILEI, [1615]2009, p. 65-66).

Os desdobramentos dessas questões podem conduzir pelo menos a dois caminhos de reflexão quanto à relação sociedade e natureza. Inicialmente, que as possibilidades de realizar observações, investigações, experimentos e ações da humanidade sobre o meio, deveriam ter tão pouca limitação quanto o tamanho de "nossa ignorância", abrindo-se mão, por exemplo, de verdades pré-concebidas pela religião. 0 raciocínio é muito frutífero do ponto de vista instrumental, mas no campo das intervenções, necessita de forte conteúdo ético para conter os efeitos das práticas que resultem em desequilíbrios ambientais de uma forma geral.

Entretanto, na sequência de sua argumentação, Galilei ressalta a abertura de espaços para a não acomodação do pensar sobre as "coisas do mundo" e da "Natureza", fator decisivo na busca e emergência de alternativas que superem os inevitáveis desvios no que diz respeito às interfaces entre a ação humana e seus efeitos no ambiente.

René Descartes ([1630]2001), no "Discurso do Método", outro nome também mencionado por inspirar a ideia de domínio da natureza, afirmou que, com a evolução do conhecimento que estava adquirindo sobre os elementos físicos que compõem a Terra, seria possível, de um ponto de vista prático, aprimorar os ofícios para que os homens se tornassem senhores e possessores da natureza. Porém, há de se destacar considerações preliminares feitas por Descartes sobre tal consideração: primeiro ele julgou que não se poderiam manter ocultas as noções por ele adquiridas, pois seria “[...] pecar gravemente contra a lei que nos obriga a propiciar, na medida do possível o bem geral de todos os homens (DESCARTES, [1630]2001, p. 68-69)", e segundo, que estas noções devem ser empregadas adequadamente. 
Observando como Descartes ([1630]2001), no conjunto da referida obra, posiciona-se frequentemente sobre o que seria o bem geral de todos, assim como que condutas éticas devem prescindir no uso adequado dos conhecimentos, vê-se que as exacerbações do uso inconsequente da natureza e sua degradação, não deveriam ser relacionadas como sinônimos ou continuidade de seu raciocínio, assim como ocorre com Francis Bacon.

Colocando sua dificuldade na compreensão dos fenômenos particulares da natureza, que para ele correspondiam à infinidade de espécies, suas características, interações entre si e com o meio, bem como o espírito humano, Descartes apresentou uma noção relativa ao grande potencial e vastidão da natureza, e assim ponderou:

[...] é necessário que eu confesse também que o poder da natureza é tão amplo e tão vasto e que esses princípios são tão simples e tão gerais que quase não percebi um único efeito específico que eu já não soubesse ser possível deduzi-lo daí de várias formas diferentes, e que a minha maior dificuldade é comumente descobrir de qual dessas formas o referido efeito depende. [...] vejo também que são tais e em tão grande número que nem as minhas mãos, nem a minha renda, ainda que eu possuísse mil vezes mais do que possuo, bastariam para todas; de maneira que, à medida que de agora em diante tiver a comodidade de realizálas em maior ou menor número, avançarei mais ou menos no conhecimento da natureza. (DESCARTES, [1630]2001, p. 72).

Nesses fatores mediados pelas limitações do entendimento, observa-se também um desfecho do que o autor desenvolveu ao longo do "Discurso do Método", como relações de causa e efeito. Ele chegou à conclusão de que para estas particularidades da natureza há grande dificuldade em se estabelecer as causas correspondentes aos efeitos complexos que observa e, assim, de chegar-se às devidas conexões.

Apesar de atualmente ocorrerem iniciativas de ir além da linearidade entre causas e efeitos no entendimento dos fenômenos ambientais, este raciocínio tem sido predominante desde então, devido ao seu alto poder explicativo. Naquela época, juntamente com o uso do seu "Cogito, ergo sum", René Descartes ofereceu elementos para se chegar além das explicações míticas ou sobrenaturais, alavancando várias possibilidades de racionalização de fenômenos.

Com suas contribuições, resolveu inúmeras questões nos domínios matemáticos e metodológicos, que tiveram grandiosos desdobramentos para o progresso do conhecimento. Contudo, no entendimento da natureza e mais ainda quanto à interferência humana sobre ela, trouxe, na sua observação conscienciosa, a dificuldade quanto à compreensão da infinidade de relações existentes, colocando ainda, em sequência, a extensão das ações humanas no tempo, afirmando que

[...] apesar de ser verdade que cada homem deve procurar, no que depende dele, o bem dos outros, e que é propriamente nada valer o não ser útil a ninguém, é verdade também que os nossos cuidados devem estender-se para mais longe do tempo presente, [...] realmente, quero que se saiba que o pouco 
que aprendi até agora não é quase nada em comparação com o que ignoro, e que não desanimo de poder aprender [...]. (DESCARTES, [1630]2001, p. 73).

Associando esta perspectiva posta há mais de quatro séculos à ampliação da sistematização dos efeitos das práticas humanas interferindo nas "particularidades naturais", tornando-os mais evidentes na atualidade, pode-se observar que levantar a necessidade de preocupação com as gerações futuras deveria ser muito mais que uma novidade trazida por um conceito de desenvolvimento sustentável. Esta negligência é um sintoma persistente da falta de consideração ou extrapolação das limitações do ser humano diante da natureza ou considerando-se inserido nela.

Até meados do século XVII, não se havia configurado um cenário de rápidas transformações no mundo "dito" civilizado e/ou conhecido. Apesar de se passarem guerras, ascensão e queda de impérios e nações, além do início da expansão colonial, ainda não havia ocorrido a revolução da produção industrial e a explosão populacional nas cidades. À revelia das grandes transformações que marcaram a configuração do mundo, e que viriam a acontecer em quase um século e meio à frente, os problemas ambientais, a desigualdade social e a baixa qualidade de vida já se antecipavam.

Com as pessoas passando a habitar as cidades mais intensamente, a natureza se tornava um elemento que ficava "fora dos muros" ou para além de suas fronteiras, presente nos campos agrícolas, nas florestas ou nas colônias, cabendo-lhe um elevado grau de perfeição. Diferenciavam-se, assim, um ambiente bastante precário com relação a condições de saneamento e higiene, densamente povoado e injusto, dos campos e florestas, onde ar e água eram puros, existiam frutos em abundância e a possibilidade uma vida boa e saudável. Em análise das representações da natureza por meio da arte, Raffaelli e Makowiecky (2000) mostraram tais diferenciações, bem como as representações mimetizavam-se com as condições de vida, os anseios humanos e suas tentativas de compreensão dos fenômenos naturais na Idade Moderna.

Para Thomas (1988), no século XVII, as pessoas que amavam o campo ainda não odiavam necessariamente as cidades, mas uma combinação literária e de fatos sociais, gerou no século seguinte uma tensão entre os anseios e benefícios que se tornavam mais evidentes na vida do campo, para ele excessivamente idealizada, em contraponto ao infatigável e degradante processo de urbanização. 0 autor também observa a desigualdade intrínseca ao acesso à "vida no campo" naquele período, pois,

Por essa época, os moradores das cidades já começavam a idealizar a cabana do campo, como seu teto de colmo, sua fumaça espiralada e as rosas em redor da porta [...] e, em fins do século XVIII, muitas "pessoas de fortuna" condescenderiam em passar um fim de semana ou outro numa "cabana 
ornamental', geralmente construída com esse propósito e equipada com um grau de luxo completamente desconhecido do habitante comum do campo. (THOMAS, 1988, p. 296).

Note-se que esse mecanismo de fuga para o campo é (ainda) e cada vez mais recorrente nos padrões atuais de moradia de grupos com maior renda que "podem afastar-se" temporariamente do ambiente "desagradável" sobre o qual têm contribuição determinante de produção, mas onde necessitam residir - a cidade -, e "aproximar-se" do ambiente "natural", saudável e tranquilo, para onde também direcionam as trajetórias da desigualdade.

Retornando àquele contexto no século XVIII, desponta Jean-Jacques Rousseau, o "amante da natureza", o admirador do "bom selvagem". Esse termo, que marcou as interpretações sobre a natureza na obra de Rousseau, seria o homem em um "[...] estado primitivo ou natural em que a corrupção não existia" (LARRÈRE, 2012, p. 13). Rousseau negou estas adjetivações que o popularizaram inicialmente até a sua morte, afirmando que o estado de natureza seria uma ficção que jamais existiu ou existirá, e que a natureza humana jamais retrocede a um estado de inocência ou igualdade (LARRÈRE, 2012).

Logo nos primeiros parágrafos da obra "Emílio ou Da Educação" [1762], Rousseau deixou claro seu posicionamento quanto à irreversibilidade da natureza humana, quando primeiro descreveu o homem sob a perspectiva de suas ações, dizendo que:

Tudo está bem quando sai das mãos do autor das coisas, tudo se degenera entre as mãos do homem. Ele força uma terra a alimentar as produções de outra, uma árvore a carregar frutos de outra. Mistura e confunde os climas, os elementos, as estações. Mutila seu cão, seu cavalo, seu escravo. Perturba tudo, desfigura tudo, ama a deformidade e os monstros. Não quer nada da maneira como a natureza o fez, nem mesmo o homem; é preciso que seja domado por ele, como um cavalo adestrado; é preciso apará-lo à sua maneira, como uma árvore de seu jardim (ROUSSEAU, [1762]2004, p. 7).

E logo em seguida, quando postulou a retirada dessas formas de agir do ser humano (o que poderia ser considerado um retorno ao possível estado de natureza), deixou claro que nada sobraria, pois,

Sem isso, tudo iria ainda pior, e nossa espécie não quer ser moldada pela metade. No estado em que agora as coisas estão, um homem abandonado a si mesmo desde o nascimento entre os outros seria o mais desfigurado de todos. Os preconceitos, a autoridade, a necessidade, o exemplo, todas as instituições sociais em que estamos submersos abafariam nele a natureza, e nada poriam em seu lugar. Seria como um arbusto que o acaso faz nascer no meio de um caminho, e que os passantes logo fazem morrer, atingindo-o em todas as partes e dobrando-o em todas as direções (ROUSSEAU, [1762] 2004, p. 7).

De acordo com Becker (2014), o que Rousseau considerou um estado de miséria é diferente do que outros autores modernos pensavam, pois isto não estava associado ao estado 
de natureza, considerado pelos defensores da racionalidade como miserável, um estado de ignorância (ou pré-social). A verdadeira miséria, relativa a privações dolorosas e ao sofrimento do corpo e alma, tinha origem dos descaminhos da trajetória civilizacional humana; quando Rousseau a retratava deixava bem claro que não deveriam se atribuir outras razões para ela, pois considera que o homem causa suas próprias desgraças, ela é fruto de suas escolhas ao longo da história (e não da providência divina ou a natureza), e ele a demonstrava porque só o próprio homem poderia desfazê-la (BECKER E BECKER, 2014).

E percebe-se que é dessa forma que Rousseau construiu sua noção de como se daria a relação entre sociedade e natureza, partindo do homem e de seu processo de "desnaturação", que ocorre quando o homem se torna um adestrador e servo tanto das artes e dos ofícios, como de sua própria espécie e dos outros animais (ROUSSEAU, [1755]1999, [1762]2001).

No "Discurso sobre os fundamentos da desigualdade entre os homens" [1755], Rousseau criticou o excesso de racionalidade em detrimento da sensibilidade, fator que afastaria ainda mais o ser humano de seu estado natural e, por mais que o estado de natureza fosse hipotético ou especulativo, este filósofo ofereceu bases para refletirmos sobre um estado de existência menos injusto, corrupto e desigual, o que poderia, no tempo atual, definir parte do que se pensa como sustentabilidade.

Para Santos (2008), o conceito de natureza aparece de forma polissêmica na obra de Rousseau, com uma grande possibilidade de obtenção de sentidos, em que estão sempre postas oposições entre natureza e artificialidade, bondade natural e maldade existente no mundo civilizado. De acordo com Becker (2013, p.32), Rousseau ([1755]1999, [1762]2001) apresenta uma defesa estética e nostálgica da natureza, que "[...] serve para ilustrar o meio no qual emergem a vida e as ações humanas. A ideia subjacente a estas descrições é a da degeneração e do adestramento humano que derivam de suas desregradas e imprudentes ações", as quais se impõem sobre a harmonia do meio natural.

Além da relação sociedade e natureza e da própria natureza humana, Rousseau também abordou outros fatores determinantes em se tratando dessas questões: a desigualdade entre os homens, a responsabilidade ética e a participação política. Quanto à desigualdade, atrelada à moral e à política, afirmou:

Concebo, na espécie humana duas espécies de desigualdade: uma, que chamo de natural ou física, porque é estabelecida pela natureza, e que consiste na diferença das idades, da saúde, das forças do corpo e das qualidades do espírito, ou da alma; a outra, que se pode chamar de desigualdade moral ou política, porque depende de uma espécie de convenção, e que é estabelecida ou, pelo menos, autorizada pelo consentimento dos homens. Consiste esta nos diferentes privilégios de que gozam alguns com prejuízo dos outros, como ser mais ricos, mais honrados, mais poderosos do que os outros, ou mesmo fazerem-se obedecer por eles (ROUSSEAU, [1755]1999, p. 245). 
Ainda no "Emílio ou da Educação", é muito pulsante a ideia de que a liberdade nos diferencia dos outros seres, mas a forma (degenerada) como a utilizamos e a direcionamos em associação com os conhecimentos adquiridos (mais pelos excessos do que pela sua ampliação), é originária de um problema ético, que se torna político, na medida em que determina as ações dos homens e de suas instituições (ROUSSEAU, [1762]2001).

Em se tratando da complexidade das questões ambientais, considera-se que este ponto é muito pertinente nos debates e problemas da atualidade, pois a presença ou ausência de responsabilidade ética, de fato implica diretamente na forma de participação política diante delas.

Cassirer (1999) observou o fato de que, naquele instante do século XVIII, o mundo repousava sob a segurança da ascensão da razão e as coisas haviam assumido formas reais e de valor determinado. A capacidade de determinação e delimitação do homem havia assumido um importante papel em sua subjetividade, ponto no qual Rousseau surgiu como o primeiro pensador a questionar tal segurança, negando as formas estabelecidas no que diz respeito à ética, política, religião, literatura ou filosofia (CASSIRER, 1999). Para esse autor, a obra de Rousseau contribui mais para um movimento constante de renovação do pensamento, situandose aí seu caráter revolucionário, do que para ser seguido como uma doutrina fixa.

Compreendendo Rousseau no conjunto dos pensadores modernos, pode-se dizer que também nele há separação entre homem e natureza. Mas, por meio dos movimentos entre as virtudes do "homem natural" e a degeneração do "homem civil", o autor estabelece a própria a natureza humana - que sempre se encantará com tudo que há de sublime na natureza física como um elemento de retorno ou reencontro com uma melhor condição moral. Inspirado na criação desse elo tão caro entre homem e natureza, possibilitado pelo pensamento de Rousseu, Santos (2008, p. 40) afirmou que,

Por mais que se queira, parece que não é possível separar, de forma absoluta, a natureza humana da própria natureza física. Já que não pode restabelecer sua harmonia perfeita e originária em seu estado de natureza, o homem, pelo menos, pode reparar um pouco esse mal, que é fruto de sua vivência social, reaprendendo a conviver melhor com a natureza. Ao menos isso ele pode!

É notório como o pensamento de Rousseau, já naquele momento, nos conduz à dificuldade de lidar com a ação humana sobre a natureza, mas que pela recuperação moral, seria possível um caminho de reparação dos danos, algo que se aproxima da noção atual de mitigação, a qual se tem desvirtuado pela sua aplicação de forma estratégica e condicionada.

Também pensando nesse potencial, é difícil observar a persistência dos descaminhos que se agravaram com o crescimento industrial e todas as mudanças que se seguem no processo de desenvolvimento do modo de produção capitalista. 0 que dizer da extrema destruição da flora, 
da fauna e do solo, da desumana exploração de minérios, da escravidão que já ocorria nos tempos de Rousseau e continuavam nas colônias? Quanto mais foram diminuindo as limitações técnicas, mais os danos à natureza e ao próprio homem aumentaram, e só ganhariam um lugar de importância na agenda política da humanidade (não para vias de efetiva resolução...) quando ocorreram as grandes catástrofes sociais e ambientais no século XX.

De Bacon a Rousseau, passou-se, portanto, de uma condição de desvelamento dos segredos da natureza e de como ela poderia ser um instrumento para o progresso tecnológico da civilização, a uma negação e crítica desse processo, já que dele não parecia sobrar muita coisa, além de desigualdades e corrupção. Caso os governantes, cientistas e outros atores sociais formadores de opiniões ou "da ação", fossem mais atentos a tais considerações, a sociedade não retroagisse constantemente no sentido da geração de um ambiente mais harmonioso.

E duzentos anos após Rousseau ter expressado suas inquietações, estas não cessaram, tal como foi posto por Arendt (2014, p. 02), ao afirmar que "0 artifício humano do mundo separa a existência humana de todo ambiente meramente animal, mas a vida mesma permanece fora desse mundo artificial, e por meio da vida o homem permanece ligado a todos os outros organismos vivos", situando, assim, invariavelmente, o ser humano no mundo natural a despeito da sua capacidade de artificialização.

Arendt (2014, p. 3-6) também levantou a dificuldade de se encontrar soluções para as questões da humanidade e seu ambiente a partir de um conhecimento eminentemente racional, considerando que "O problema tem a ver com o fato de que as 'verdades' da moderna visão científica do mundo, embora possam ser demonstradas em fórmulas matemáticas e comprovadas tecnologicamente, já não se prestam à expressão normal no discurso e no pensamento", e com certo pessimismo, expressando uma perplexidade similar diante do comportamento humano assim como Rousseau em seu tempo, continuou: “[...] pode suceder que nós, [...] jamais sejamos capazes de compreender, isto é, de pensar e de falar sobre as coisas que, no entanto, somos capazes de fazer", deixando a seguinte pergunta: "O que estamos fazendo?".

Para Serres (1990, p. 20), "Devoradora, a história permanece indiferente à natureza" e, atribuindo mais elementos à questão colocada por Arendt (2014), podemos unir a ela sua percepção, na qual também se leva em conta que "As relações entre o homem e o mundo completam-se, transformam-se e invertem-se até" (SERRES, 1990, p. 37), derivando assim, mais um questionamento: 0 que estamos fazendo diante dessa histórica indiferença à natureza, pela qual, nas relações homem-meio, as sociedades tendem mais a suprimir do que a complementar? E é a partir da reflexão sobre essa pergunta, que se inicia a sessão anterior, discutindo o viés de ação por meio da prática científica. 


\section{VALORES DO PESQUISADOR E ATIVIDADE CIENTÍFICA: DO SENSO COMUM À COMPLEXIDADE OU A COMPLEXIDADE DO SENSO COMUM?}

Questionamentos sobre o que é ou não é científico ainda são comuns e por vezes necessários. Porém, no desenrolar do século XX e primeiros anos do XXI, surgiram discussões mais profundas que ultrapassam ideias rígidas de cientificidade. Isto se deu, em grande medida, pela acelerada evolução tecnológica, pela ocorrência de eventos sociais e naturais extremos (terremotos, movimentos sociais, grandes guerras, etc.) e à retomada de teorias científicas cada vez mais complexas.

Isso também aconteceu por conta de grandes preocupações oriundas do final do século XIX a meados do século XX no que diz respeito à definição dos requisitos formais para atribuir o status científico a uma determinada pesquisa. Os métodos, teorias e modelos criados e consolidados até então, em confronto com a realidade em profunda transformação tecnológica e social, começaram a ser repensados ou contestados, estabelecendo-se dilemas, paradoxos e contradições.

Ainda assim, até meados do século passado, em virtude dos grandes avanços científicos que intervinham no avanço tecnológico da humanidade, não era tão incomum a impressão de que a produção relativa à epistemologia da ciência e seus métodos já havia solucionado diversos desses dilemas. Círculos científicos, institutos de pesquisa, meios de publicação consagrados e grandes universidades, tinham regras estabelecidas sobre o que era conhecimento científico e senso comum; ciência exata ou ciência humana; quanto ao uso de experimentação ou abstração; subjetividade ou objetividade, etc. Determinava-se com certa segurança, inclusive, qual o escopo inerente a cada disciplina ou área de conhecimento. A racionalidade é imperativa e

[...] se estabelece como um dos principais determinantes das relações sociais, pelo fato de proporcionar e, ao mesmo tempo, fundamentar o desenvolvimento tecnológico. A ciência, dada sua força de explicação e transformação da tecnologia e, consequentemente, da estrutura social, é reconhecida como forma privilegiada de entendimento do mundo (SCHOR, 2007, p. 338).

Mesmo considerando a existência de outras correntes filosóficas importantes como a marxismo e a fenomenologia, o positivismo lógico determinava as linhas gerais para estabelecer tais definições, exclusões ou separações categóricas, principalmente entre o que seria ou não seria considerado científico. Esta questão demandava grandes esforços de quem analisava o curso e métodos da ciência, deixando outras em segundo plano,

[...] a tecnologia estava ligada à ideologia comteana do progresso científico e humano. Esse conceito de progresso inevitável tinha sido inicialmente enunciado, no final do século XVIII, por Condorcet [...] assim, a filosofia de 
Condorcet e de Comte fundiram-se para tornar-se uma peça central da modernidade. (SHINN, 2008, p. 47).

Em meados do século XX, começaram a repercutir na sociedade científica as obras de estudiosos como Karl Popper e Thomas Kuhn, as quais se confrontavam com os preceitos estabelecidos pelo positivismo exacerbado. Emergiram assim, outras questões como: o problema da indução, o rigor nos testes de hipótese e experimentos, além do exercício da autocrítica em Popper; a capacidade de persuasão do pesquisador e o papel da comunidade científica na aceitação e consolidação de um paradigma em Kuhn. Nestas ideias, já se percebe a incorporação dos valores, decisões e atitudes dos cientistas e da comunidade acadêmica nas atividades de pesquisa e difusão do conhecimento.

Popper (1982), por meio de seu racionalismo crítico, afirmou que é impossível admitir a existência do conhecimento humano, sem aceitar por implicação, ao mesmo tempo, que ele é feito de arbitrariedade e caprichos individuais. Também recuperou o princípio kantiano da autonomia, destacando que no campo da ética e do conhecimento moral, "[...] sempre que defrontamos um comando dado por uma autoridade devemos julgar, criticamente, se obedecê-lo será um ato moral ou imoral”. (POPPER, 1982, p. 54).

Percebe-se que Popper levantou a necessidade de consideração dos valores do pesquisador, uma vez que é a partir de seus julgamentos e capacidade de falsear e testar suas conjecturas, que seriam determinados os tipos de conhecimento os quais visavam rejeitar ou corroborar e assim, dar continuidade aos trabalhos de investigação.

$\mathrm{Na}$ atualidade, de acordo com Oliveira (2011), esta autonomia do cientista individualmente, refletir-se-ia nas formas de autonomia da ciência e na maneira como ela vem sendo reivindicada. Assim como ocorre com os valores e o senso comum, sitou a autonomia em função de sua influência e efeitos da atividade científica. "Dada a importância desse requisito, pode ser chamada autonomia com responsabilidade social, ou autonomia socialmente responsável" (OLIVEIRA, 2011, p. 557).

Kuhn ampliou a noção de escolhas e atitudes de um pesquisador individualmente para o grupo ou comunidade científica, afirmando que "Homens cuja pesquisa está baseada em paradigmas compartilhados estão comprometidos com as mesmas regras e padrões da prática científica". (KUHN, 1998, p. 30).

A partir de sua obra, foi possível realizar análises das “[...] relações de poder dentro e fora da comunidade científica e assim esclarecer os mecanismos através dos quais se cria 'consenso científico' e se orienta o desenvolvimento da ciência [...]” (SOUZA SANTOS, 1989, pg.137). Suas concepções de paradigma e comunidade acadêmica, respectivamente, são fundamentais no entendimento das obras de Boaventura e Lacey. 
Na passagem para a ciência pós-moderna, juntaram-se a estas visões a respeito da atividade científica, progressos teóricos e técnicos, além de problemas afirmativos que surgiam e ainda existem. Tudo isto em um movimento no qual a ciência não parecia mais ocupar um lugar diferenciado, superior, neutro ou a priori, tal como definido por Gödel que ousadamente questionou a matemática ao afirmar que sobre ela havíamos conferido certa invulnerabilidade.

Antes de sua Teoria da Incompletude, nunca havia sido colocada à prova a ideia de que os matemáticos ocupavam "No castelo altaneiro da Razão Pura, [...], supremos, a torre mais elevada, seus métodos consistindo em pensar, puro pensar." (GOLDSTEIN, 2008, pg. 15). Este tipo de investida de Gödel foi mais um contributo para fomentar novas e retomar antigas questões invisibilizadas em outros momentos da história da ciência, fundamentando a impressão de crise na ciência moderna. Tratando da gênese da pós-modernidade, diz-se que:

A descrença na ciência e as dúvidas acerca de muitos aspectos relacionados à modernidade proporcionaram, assim, um terreno fértil para a reflexão antimoderna e para a emergência da visão de mundo pós-moderna. A metade do século XX, com suas novas formas de cognição e de tecnologia, é também comumente associada à gênese da pós-modernidade. (SHINN, 2008, p. 50).

Então, neste momento entendido como pós-modernidade, esta reflexão "anti-moderna" é bastante vívida nas ideias de alguns autores, ora moderadamente, ou então como forma de realmente romper com a ciência moderna em alguns pontos.

Souza Santos (2008), por exemplo, justificando a formação de um novo senso comum, afirma que a ciência moderna nos ensina pouco sobre a maneira de estar no mundo e "[...] produz conhecimentos e desconhecimentos. Se faz do cientista um ignorante especializado faz do cidadão comum um ignorante generalizado [...]" (SOUZA SANTOS, 2008, p. 88).

A ideia de Boaventura, que aproxima senso comum e conhecimento científico, constituise numa perspectiva revolucionária da ciência pós-moderna. Vale destacar que o novo senso comum tem como base uma construção teórica do autor bem mais complexa em relação à ideia geral que se tem do termo e,

[...] corresponde a uma elaboração do senso comum enquanto crítico dele mesmo. Essa reflexividade analítica e crítica do senso comum é o que lhe permite estar muito mais em conformidade com as ideias de significação e de verdade. A lição não é fundamentalmente diferente daquela das ciências. Mas estas últimas nos ajudam a precisá-la e a ampliá-la. (PATY, 2003, p. 12).

Algumas razões podem ser levantadas na dificuldade de formação de um novo senso comum. 0 próprio Boaventura (2008) afirma ser uma proposta com dimensões de certa forma utópicas e libertadoras. Neste contexto em que "todo conhecimento visa tornar-se senso comum" (SOUZA SANTOS, 2008, p. 88), no plano da produção e difusão do conhecimento, existem algumas implicações de ordem prática. 
São questões principalmente associadas ao acesso desigual à educação e sua dificuldade de conexão com saberes tradicionais, que passam por um processo ainda lento de maior valorização, entretanto positivamente têm originado um movimento contrário de aproximação, ou seja, destes saberes para a ciência. Um ponto que tem avançado nesse sentido é o da institucionalização e incentivo a estudos multidimensionais e interdisciplinares, tais como sob a perspectiva ambiental, requisitos primordiais apontados pelo autor para existência do novo senso comum.

Uma vez que “[...] não podemos conceber a compreensão ou a comunicação sem fazer referência ao senso comum que é uma espécie de terreno fértil para nosso pensamento e nossas ações" (PATY, 2003, p. 09), também existem dificuldades relativas aos avanços nas tecnologias da informação devido à sua natureza contraditória. Ao mesmo tempo em que ocorre uma ampliação sem precedentes das possibilidades de acesso a informação, a facilidade e a falta de critérios na veiculação de notícias, textos e opiniões dificultam as chances de algo realmente fecundo ser difundido satisfatoriamente. Este tem sido um grande entrave à propagação de interesses difusos diante de questões ambientais, pois há muita dificuldade de acompanhamento de informações equivocadas, que se sobrepõem aos problemas de fato em uma dada realidade.

Assim, diante deste contexto, apesar dessa aproximação com o senso comum mostrar-se como um movimento positivo dos pontos de vista da influência e efeitos da ciência, diminuindo lacunas entre ciência e sociedade, infelizmente não é nessa relação que esta possibilidade tem se manifestado mais evidentemente. Essa diminuição de lacunas se dá, tendo sua relevância garantida na prática, por meio da produção de tecnologia, uma característica que persiste desde a modernidade.

É importante lembrar que existem discussões mais complexas sobre a ideia de "tecnociência", como em Latour (2000), que trazem vertentes interessantes de pensamento sobre a relação ciência e tecnologia, relativizando a ideia exposta acima.

Contudo, baseando-se em Lacey e considerando o grande peso desta característica, podese chegar contemporaneamente a definições de atividade científica como sendo "[...] um padrão de racionalidade, que explica e desenvolve a tecnologia [...]" (SCHOR, 2007, p. 337).

Nessa perspectiva de seus efeitos e enfatizando exemplos de ordem ambiental, social e tecnológica, Lacey $(1998 ; 2008 b)$ propõe que esta racionalidade seja analisada em termos de valores cognitivos e não-cognitivos do pesquisador e da comunidade científica da qual faz parte, ao invés de pautar-se em um conjunto de regras aparentemente imaculadas e descontextualizadas persistentes na academia. Nela,

Valores sociais, éticos e pessoais podem legitimamente afetar não apenas decisões feitas nos momentos não centrais, mas também a dinâmica e a textura das práticas científicas: quando, onde, e por quem são conduzidas, quão rápida 
e amplamente são desenvolvidas, e se são acolhidas ou restringidas em determinadas sociedades. (LACEY, 2008b, p. 84).

A definição de teoria científica proposta por Lacey encontra-se inserida no plano das limitações humanas e no contexto da sociedade capitalista e materialista, “[...] sendo a capacidade explicativa do mundo da experiência vivida e de seus objetos o ponto crucial de sua afirmação como científica" (SCHOR, 2007, p. 341). Ou seja, uma teoria científica que "primordialmente e acima de tudo forneça sentido ao mundo da experiência vivida" (Lacey, 1998, p. 106). Tem-se assim, a passagem de uma situação de produção científica e tecnológica desconectada da realidade para uma ciência que responde, junto com outros fatores, pela configuração social e ambiental.

$\mathrm{Na}$ definição de valores cognitivos essenciais ao cientista - sobretudo neutralidade, imparcialidade e autonomia - Lacey (2008a) apresenta um conjunto de juízos científicos norteadores, cujos principais são: a definição de estratégia de trabalho, adequação da teoria à realidade empírica observada (pesquisa situada no contexto), verificação de sua consistência interna, existência de elevado poder explicativo e simplicidade.

Os valores cognitivos e juízos apresentados por Lacey são sintonizados com as obras de diversos autores. Ele indica contribuições que oferecem caminhos metodológicos seguros e ajudam a dissociar o conteúdo dos valores não-cognitivos dos cognitivos, como a fecundidade na geração de quebra-cabeças de uma pesquisa em Kuhn, a falseabilidade de Popper e a eficácia instrumental de Putnam. (cf. LACEY, 1999, p. 52-53).

Estes juízos científicos corretos não serão alcançados isoladamente, mas sim por meio do diálogo e interações entre a comunidade científica em diversas instituições da sociedade. A aceitação correta de uma teoria ocorrerá se houver o endossamento de hipóteses e teorias que contenham valores cognitivos em alto grau (LACEY, 2008b).

Lacey (2006) também recupera o princípio de precaução, discordando das críticas sobre uma possível intrusão da ética na autonomia da ciência e de que o princípio pode ser "irrealista". Este é outro ponto que interfere diretamente nos efeitos da implantação de inovações tecnocientíficas e remete às imbricações entre ciência e ambiente.

O princípio é composto de duas propostas: a cautela face à aplicação tecnológica de resultados científicos bem confirmados e a importância de empreender investigação em áreas comumente pouco pesquisadas. Do ponto de vista prático,

[...] representa uma posição que pode ser tomada com respeito à aplicação do conhecimento tecnocientífico. [...] Esses valores (éticos concernentes aos direitos humanos) informam avaliações da seriedade dos riscos e, portanto, de qual deve ser o nosso nível de confiança de que um dano potencial pode ser adequadamente evitado ou regulado. A elaboração responsável dessas avaliações requer a pesquisa, entre outras coisas, dos riscos sociais ou ecológicos [...]. (LACEY, 2006, p. 374, comentário inserido). 
Assim, percebe-se que suas ideias sempre convergem para o sentido de acentuar a responsabilidade dos cientistas, considerando que a elas “[...] estendem-se também às deliberações sobre a legitimidade das aplicações do conhecimento científico" (LACEY, 2011, p. 489). Esta responsabilidade deve ir além da previsão de riscos e primar pelos valores cognitivos, o que garantindo efeitos cada vez mais positivos com relação à produção de tecnologias e sua aplicação. Oliveira (2000) atribuiu o termo "epistemologia engajada" à produção de Lacey. Nela, é marcante a busca de comprometimento científico com a sociedade e natureza, o que certamente é um dos grandes desafios da ciência pós-moderna, já que a inovação tecnológica persiste em avançar a passos largos.

Ao levantar as dificuldades de compreensão da realidade por meio do pensamento lógico-dedutivo e simplificador, em que a ambiguidade e incerteza são rejeitadas, Morin (2011) trouxe elementos para o "pensamento complexo", uma alternativa (e anseio) de interpretação das relações humanas e das pessoas com a natureza, consideradas de difícil redução tanto epistemologicamente como em termos práticos. Entretando, Morin (2011) não defende um abandono total dessa lógica, mas que ocorra uma combinação dialógica entre os segmentos que constumeiramente são separados, transgredindo-se os buracos negros onde esse modelo deixa de ser operacional. Ainda Morin (2003, p. 13) afirma que “[...] a hiperespecialização impede de ver o global (que ela fragmenta em parcelas), bem como o essencial (que ela dilui)".

Dessa forma, abrem-se espaços para as refletir diante das incertezas dos fatos naturais e sociais, partindo do ponto de que a natureza dos problemas (ou soluções) torna-se cada vez mais complexa. Complexa, não necessariamente complicada. A complexidade apresenta como desafio um encontro dos fios condutores entre processos fragmentados, em que oposições coexistem, complementam-se e retroalimentam-se, num anel gerador "no qual os produtos e os efeitos são produtores e causadores do que os produz". (MORIN, 1999, p. 27). Neste anel recursivo, Morin (1999) propõe a superação da noção de regulação pela de autoprodução e de auto-organização.

No sentido de refletir para além dos fatos consumados e na tentativa de "compreensão" de um processo estudado, ao invés de insistir na ideia de "transformação" bilateral do ambiente, polarizando aspectos de forma linear, é bastante pertinente a noção de anel retroativo também discutida por Morin (1999). 0 anel retroativo

[...] permite o conhecimento dos processos de auto-regulação. Rompe com o princípio de causalidade linear: a causa age sobre o efeito, e este sobre a causa [...] possibilita, na sua forma negativa, reduzir o desvio e, assim, estabilizar um sistema. Na sua forma mais positiva, o feedback é um mecanismo amplificador; por exemplo, na situação de apogeu de um conflito: a violência de um protagonista desencadeia uma reação violenta que, por sua vez, determina outra reação ainda mais violenta. Inflacionistas ou estabilizadoras, as retroações são numerosas nos fenômenos econômicos, sociais, políticos ou psicológicos (MORIN, 1999, p. 27). 
Estas abordagens incluem percepções mais abertas diante das difíceis questões a solucionar no amplo e interconectado espectro dos fenômenos ambientais. Além disso, proporcionam um caminho a partir de noções que se foram diluindo na ciência moderna, tais como a necessidade de se ter um rigor não necessariamente pautado na lógica matemática, da valorização da autocrítica, da responsabilidade social e da recuperação dos valores do pesquisador na atividade científica (LACEY, 2011).

Tem-se dessa forma, três possibilidades de aproximação entre ciência e ambiente: os benefícios gerados por novas formas de observação e tratamento dos objetos estudados, a produção de um conhecimento que chegue à população em geral e a geração de tecnologias mais adequadas ao equilíbrio com o meio. Busca-se, assim, construir:

Uma ciência afinada não com a postura de controle, mas com a de autocontrole, nas relações da humanidade com a natureza [...] Tendo a comunidade científica que dedicar uma parte de seu tempo e energia à reflexão sobre seu papel na sociedade, [...] diminuição no ritmo de progresso da ciência, segundo os parâmetros com que tal progresso é hoje avaliado. Talvez os cientistas achem esse um preço muito alto a ser pago. Cabe então deixar claro que o preço é de fato alto, mas compensador" (OLIVEIRA, 2008, pg. 114).

\section{CONSIDERAÇÕES FINAIS}

Ao analisar a passagem da modernidade para a pós-modernidade, percebe-se que a diminuição de lacunas entre ciência, sociedade e natureza parece persistir em avançar mais rápido do ponto de vista da tecnologia do que na difusão mais satisfatória do conhecimento produzido, tem-se na obra de Lacey caminhos objetivos para lidar com esta questão.

De acordo com sua abordagem bem estruturada e audazes afirmações para propor que a ciência não é livre de valores, pode-se considerar que o autor traz uma contribuição que beira a urgência no que diz respeito a ideias persistentes e noções difusas a respeito da neutralidade, autonomia e imparcialidade da ciência. Assim sendo, com relação aos cuidados com os efeitos da atividade científica, tem-se na obra de Lacey uma importante base para a revisão da atuação do pesquisador nesse sentido de engajamento e contextualização.

É necessário, porém, no plano da influência da atividade científica, que se busque uma maior efetividade de propostas como a de Boaventura. Apesar das dificuldades apresentadas para alcançar o novo senso comum, essa é uma ideia que não se pode perder de vista na dita "sociedade da informação". Nesta possibilidade, residem as maiores transformações sociais e humanas, nas quais as contribuições da ciência podem influenciar decisivamente na produção de configuração de um ambiente mais equilibrado e justo. 
Como forma de lidar com a recorrente e ampla diversidade de efeitos adversos das intervenções humanas, no processo de construção conceitual e empírico da pesquisa, bem como nas interpretações e informações geradas e difundidas, considera-se imprescindível levar em conta noções como a de Edgar Morin, que contribui signitivamente, da cognição à ação, na tentativa de superar os pragmatismos que envolvem a observação e resolução de questões ambientais.

\section{REFERÊNCIAS}

ARENDT, Hannah. A condição humana. Tradução: Roberto Raposo, revisão técnica: Adriano Correia. 11. Ed. Rio de Janeiro: Forense Universitária, 2014.

BACON, F. A Sabedoria dos Antigos. Tradução, Gilson César Cardoso de Souza. São Paulo: Unesp, 2002.

BECKER, Evaldo. NATUREZA, ÉTICA E SOCIEDADE EM ROUSSEAU. Cadernos de Ética e Filosofia Política, [S.I.], n. 21, p. 3142, Jul. 2013. ISSN 2317-806X. Disponível em:

http://www.revistas.usp.br/cefp/article/vi ew/58318. Acesso em: jan. 2015.

BECKER, EVALDO; BECKER, Michele Amorim. Contribuições de Rousseau ao entendimento dos desastres socioambientais contemporâneos. Trans/Form/Ação (UNESP. Marília. Impresso), v. 37, p. 111-126, 2014. Disponível em: http://www2.marilia.unesp.br/ojs-

2.4.5/index.php/transformacao/article/vie w/3884/2899. Acesso em: jan. 2015.

BRUNO, Giordano. Sobre o infinito, o universo e os mundos. São Paulo: Abril Cultural, 1973. 291 p. Col. Os pensadores, v. 12.

BRUSEKE, Franz Josef. A descoberta da contingência pela teoria social. Soc. estado, Brasília, v. 17, n. 2, p. 283-308, Dez. 2002. Disponível em: http://dx.doi.org/10.1590/S010269922002000200004. Acesso: fev. 2015.

CASSIRER, Ernst. A questão Jean-Jacques Rousseau. Trad. Erlon José Paschoal, Jézio Gutierre. São Paulo: Editora UNESP, 1999.

GALILEI, Galileu. Ciência e Fé: cartas de Galileu sobre o acordo do sistema copernicano com a Bíblia. 2. ed. São Paulo: Editora UNESP, 2009.

GOLDSTEIN, R. Incompletude: a prova e o paradoxo de Kurt Gödel. Tradução: Ivo Korytowski. São Paulo: Companhia das Letras, 2008. p. 242.

HORA, J. S. S. A natureza em Bacon e a recepção da sua filosofia nas discussões ambientais. 1‥ ed. Porto Alegre: Redes Editora, 2015. v. 1.108 p.

KUHN, T. S. A estrutura das revoluções científicas. 5.ed. São Paulo: Perspectiva, 1998.

LACEY, H. Valores e atividade científica. São Paulo: Discurso Editorial/Fapesp, 1998. Is science value-free? Values and scientific understanding. [e-book]. Londres e Nova York: Routledge, 1999. 0 princípio de precaução e a autonomia da ciência. Sci. stud. [online]. 2006, v.4, n.3, p. 373-392. Disponível em: http://dx.doi.org/10.1590/S1678-

31662006000300003. Acesso em: 15 mai. 2012.

Ciência, respeito à natureza e bemestar humano. Sci. stud. [online]. 2008a, v.6, n.3, p. 297-327. Disponível em: http://www.scielo.br/scielo.php?script=sci arttext\&pid=S1678-31662008000300002. Acesso em: 10 mar. 2012.

Aspectos cognitivos e sociais das práticas científicas. Sci. stud. [online]. 2008b, v.6, n.1, p. 83-96. Disponível em: http://www.scielo.br/scielo.php?script=sci arttext\&pid=S1678-31662008000100004. Acesso em: 15 mai. 2012.

A imparcialidade da ciência e as responsabilidades dos cientistas. Sci. stud. [online]. 2011, v.9, n.3, p. 487-500. 
Disponível

em:

http://www.scielo.br/scielo.php?script=sci arttext\&pid=S1678-31662011000300003.

Acesso em: 05 jun. 2012.

LARRÈRE, Catherine. JEAN-JACQUES ROUSSEAU: O RETORNO DA NATUREZA? Cadernos de Ética e Filosofia Política, [S.I.], n. 21, p. 13-30, Jul. 2013. ISSN 2317-806X. Disponível em: http://www.revistas.usp.br/cefp/article/vi ew/56546. Acesso em: 27 Mai. 2015.

LATOUR, B. Ciência em ação: como seguir cientistas e engenheiros sociedade afora. São Paulo: Ed. UNESP, 2000.

MORIN, Edgar. Da necessidade de um pensamento complexo. In: MARTINS, Francisco M.; SILVA, Juremir M. (Org.) PARA navegar no século XXI: tecnologias do imaginário e cibercultura. Porto Alegre: EDIPUCRS, 1999. 294 p., pp. 19-42.

. A cabeça bem-feita: repensar a reforma, reformar o pensamento. 8. ed. Rio de Janeiro: Editora Bertrand Brasil, 2003. 128 p.

La sfida della complessitá/ Le défi de la complexité. Firenze, Le Lettere, 2011.

OLIVEIRA, M. B. de. A epistemologia engajada de Hugh Lacey II. Manuscrito XXIII(1), 2000, p.185-203. Disponível em: http://www2.fe.usp.br/ mbarbosa/hlacey 2.pdf. Acesso em: 04 jun. 2012.

Formas de autonomia da ciência. Sci. stud. [online]. 2011, v.9, n.3, p. 527-561. Disponível em: http://www.scielo.br/scielo.php?script=sci arttext\&pid=S1678-

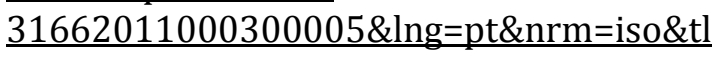
ng=en. Acesso em: 15 mai. 2012.

PATY, M. A ciência e as idas e voltas do senso comum. Sci. stud. [online]. 2003, v.1, n.1, p. 9-26. Disponível em: http://dx.doi.org/10.1590/S1678-

31662003000100002. Acesso em: 10 mai. 2012.

POPPER, K. R. Conjecturas e Refutações. Tradução: Sérgio Bath. 2.ed. Brasília: Editora Universidade de Brasília, 1982. 449 p. (Coleção Pensamento Científico, 1).

PRIGOGINE, Ilya. Nosso diálogo com a natureza. In: PRIGOGINE, Ilya. O fim das certezas: tempo, caos e as leis da natureza. São Paulo: UNESP, 1996.
RAFFAELLI, Rafael; MAKOWIECKY, Sandra. Sobre a representação da natureza na pintura ocidental: mimesis e disegno interno. Cadernos de Pesquisa Interdisciplinar em Ciências Humanas, Florianópolis, v. 1, n. 11, p. 2-19, jan. 2000. ISSN 1984-8951. Disponível em: https://periodicos.ufsc.br/index.php/cader nosdepesquisa/article/view/1693/4392.

Acesso em: 27 Mai. 2015.

ROUSSEAU, Jean Jacques. Cartas sobre os elementos de Botânica (1781). Lisboa: Typographia Chalcographica, Typoplastica, e Literaria do Arco do Cego, 1801. Disponível em: http://www.brasiliana.usp.br/bbd/handle/ 1918/03893000. Acesso em: jan. 2015.

Emílio, ou, Da educação. 3. ed. São

Paulo: Martins Fontes, 2004. 711 p.

Discurso sobre a origem $e$ os

fundamentos $d a$ desigualdade entre os homens. 2.ed. São Paulo: Martins Fontes, 1999. 330 p. (Clássicos).

SANTOS, Antônio Carlos dos. Os sentidos de natureza na filosofia de Rousseau. In: Filosofia \& Natureza: debates, embates e conexões. 1ed. São Cristóvão: Editora da Universidade Federal de Sergipe, 2008, v. 1, p. 28-41.

SCHOR, T. Reflexões sobre a imbricação entre ciência, tecnologia e sociedade. Sci. stud. [online]. 2007, v.5, n.3, p. 337-367. Disponível em: http://www.scielo.br/scielo.php?pid=S167 $\underline{8-}$

$\underline{31662007000300004 \& \text { script }=\text { sci } \text { abstract \& }}$ tlng=pt. Acesso em: 10 mai. 2012.

SERRES, Michel. O Contrato Natural. Lisboa: Instituto Piaget, 1990.

SHINN, T. Desencantamento da modernidade e da pós-modernidade: diferenciação, fragmentação e a matriz de entrelaçamento. Sci. stud. [online]. 2008, v.6, n.1, p. 43-81. Disponível http://dx.doi.org/10.1590/S167831662008000100003. Acesso em: 10 mai. 2012.

SOUZA, Maria das Graças de. A filosofia da natureza em Bacon: a herança democritiana. In: Santos, Antônio Carlos. (Org.). Filosofia e Natureza. São Cristovão, Sergipe: Editora da Universidade Federal de Sergipe, 2008, p. 17-28. 
SOUZA SANTOS, B. de S. Introdução a uma ciência pós-moderna. Rio de Janeiro: Graal, 1989.

. Um discurso sobre as ciências. 5.ed. São Paulo: Cortez, 2008.
THOMAS, Keith. $O$ homem e o mundo natural: mudanças de atitude em relação às plantas e aos animais (1500-1800). São Paulo: Companhia das Letras, 1988. 454p. 